\title{
Theoretical Study on the Mechanism of $[3+2]$ Cycloaddition Reactions between $\alpha, \beta$-unsaturated Selenoaldehyde with Nitrone and with Nitrile Oxide
}

\author{
Haydar Mohammad-Salim ${ }^{1}$, Rezan Hassan ${ }^{2}$, Hassan H. Abdallah ${ }^{3 *}$, Mohsen Oftadeh ${ }^{4 *}$ \\ ${ }^{1}$ Chemistry Department, Faculty of Science, University of Zakho, Duhok, Iraq. \\ ${ }^{2}$ Chemistry Department, college of Science, Salahaddin University-erbil, Iraq. \\ ${ }^{3}$ Chemistry Department, college of education, Salahaddin University-erbil, Iraq. \\ ${ }^{4}$ Chemistry Department, Payame Noor University, 19395-4697 Tehran, I. R. Iran.
}

*Corresponding author: Mohsen Oftadeh, Phone: (98) 3133521022, Fax: (98)3133521802 emails: m_oftadeh@pnu.ac.ir, hassan.abdullah@su.edu.krd

Received November $8^{\text {th }}, 2019$; Accepted March 25 2020.

DOI: http://dx.doi.org/10.29356/jmcs.v64i2.1111

\begin{abstract}
The reaction mechanisms of [3+2] cycloaddition (32CA) between the $\alpha, \beta$-unsaturated selenoaldehyde with nitrone and nitrile oxide were investigated theoretically using the molecular electron density theory (MEDT). Selenoaldehyde has two unsaturations which allow for the cycloaddition occurring. It was expected to undergo four regioisomeric reaction paths in two separate reactions with nitrone and nitrile oxide. The study was conducted using ab initio approach at MP2/6-31G(d) level of theory. Potential energy surfaces were generated from the energies of the stationary points involved in the mechanisms and the dominant reaction pathways were identified. It was found that Pathway 3 and 4 are the two competing reaction channels, where the cycloaddition reaction occurs at the selenium-analogue carbonyl group of selenoaldehyde. The reactivity indices were analysed at the ground state of the reactants to predict the reactivity of studied organic molecules in 32CA reactions. Analysis of the electronic structure of nitrone and nitrile oxide, the three-atomcomponents (TACs), and their participation in 32CA reactions towards selenoaldehyde allows establishing a useful classification of 32CA reactions into zwitterionin-type (zw-type) reactions involving TACs with a high zwitterionic character.
\end{abstract}

Keywords: Selenoaldehyde; nitrone; nitrile oxide; MP2; ELF; cycloaddition; MEDT.

Resumen. Se estudia teóricamente, utilizando la teoría de la densidad electrónica molecular (MEDT), el mecanismo de reacción de la cicloadición [3+2] (32CA) entre selenoaldehídos $\alpha, \beta$ insaturados con nitrona y óxido de nitrilo. El selenoaldehído tiene dos insaturaciones que permiten la cicloadición. Se esperaba que la reacción se llevara a cabo a lo largo de cuatro caminos regioisoméricos en dos reacciones separadas con la nitrona y el óxido de nitrilo. Se realizó un estudio ab initio con el nivel de teoría MP2/6-31G(d). Se generaron superficies de energía potencial a partir de las energías de los puntos estacionarios involucrados en el mecanismo y se identificaron los caminos de reacción dominantes. Se encontró que dos rutas, la 3 y la 4 , son los canales de reacción que compiten para que ocurra la cicloadición en el grupo carbonilo análogo al selenio del selenoaldheído. Se analizaron los índices de reactividad de los estados basales de los reactivos para predecir la reactividad de las moléculas orgánicas estudiadas en las reacciones 32CA. El análisis de la estructura electrónica de la nitrona y el óxido de nitrilo, de las componentes triatómicas (TACs) y de su participación en las reacciones 32CA hacia el selenoaldheído permite clasificar a las reacciones 32CA en tipo zwitteriónico (zw) que involucran a los TACs con un elevado carácter zwitteriónico.

Palabras clave: Selenoaldehído; nitrona; óxido de nitrilo; MP2; ELF; cicloadición; MEDT. 


\section{Introduction}

[3+2] cycloaddition (32CA) reaction offers one of the most versatile methods in synthesizing heterocylic compounds that have many different biological applications, catalytic ability and also act as precursors for forming a different functional group organic products [1-7]. In particular, the cycloaddition reactions of nitrones and nitrile oxides have been heavily investigated in the past, through either experimental or theoretical methods. Reactions between these nitrogen compounds with carbonyls have paved ways in the synthetic processes of isoxazoline compounds in both academia and industry which can behave as a precursor to synthesize amino acids, amino alcohols or other nitrogen containing products via the cleavage of the N-O bond in isoxazoline [8-16].

The 32CA reactions have very interesting properties, in particular the regioselectivity of which the products are formed. There are many ways that can be used to find out the most probable pathway of a particular reaction. The most common is from transition state theory to find out the mechanisms of the reaction and the most probable pathway with the lowest activation barrier. Many computational studies have been reported on the reaction between nitrones and nitrile oxides with numerous electron-rich or -deficient dipolarophiles [1726]. To elaborate on some of the studies, Zhao et al. [17] reported that the steric properties of the reactants affect heavily on the thermodynamically stable product to be formed. They utilized the density functional theory (DFT) method to investigate the reaction channels and reported a good corroboration to the experimental results without too much of a computational cost. Nacereddine and coworkers [18] also reported a good corroboration of their DFT methods to experimental results and found a good insight on the stabilization of secondary $\pi$ orbital interaction to give a low lying transition state. However, this method is very time consuming due to the calculations on the higher order saddle points in the reaction coordinate and it is often needed to be paired with other theoretical data like bond parameters and NMR calculations to get a good conclusion as shown by Bakavoli and coworkers [19]. Solvent effects and Lewis acid behaviour of the reaction have also been investigated extensively by Domingo [24]. Merino and co-workers [26] also reported that the theoretical methods used have to be scrutinized carefully as the quantitative treatment of the energy profile may not be reliable but the qualitative treatment has been found to agree with experimental data.

Another method that makes use of the Frontier molecular orbital model (FMO) [27,28] can also be used to investigate the regioselectivity of a reaction and explain the chemical reactivity differences. In fact, Nacereddine and co-workers [18] had previously conducted a theoretical investigation to find out the regioselectivity of the reactions between a nitrone derivative with substituted alkenes. Depending on the substituted alkenes, the FMO analysis found that the alkenes can behave as electrophiles and nucleophiles. Other reactivity descriptors such as Fukui indexes, local softness and local philicity have also been utilized in predicting the regioselectivity and explain the difference in reactivity of a particular reaction [29-33].

As part of our investigation, we make use of theoretical methods to find out the mechanism and regioselectivity of the reactions between nitrile oxide and nitrones with selenoaldehydes. Selenocarbonyl compounds are found to be a very reactive analogue of carbonyl compounds and the cycloaddition between the selenoaldehydes with these nitrogen compounds offers ways to incorporate selenium into an organic material [34-49]. In this theoretical paper, we investigate the mechanism of a simple nitrone and nitrile oxide with a $\alpha, \beta-$ unsaturated selenoaldehyde and discuss the difference in reactivity of the alkene and the carbonyl functional group in selenoaldehyde during 32CA reaction. The electron localisation function (ELF) topological analysis of the electronic structure associated with the $32 \mathrm{CA}$ reaction of nitrone and nitrile oxide with $\alpha, \beta$-unsaturated selenoaldehyde are explored and characterised.

\section{Computational Method}

The study was done at MP2/6-31G(d) [50-52] level of theory in Gaussian09 software package [53]. All the stationary points are optimized at the specified level of theory and the geometric parameters are reported in this paper. Further single point calculations were carried out at MP3/6-31G(d) level of theory on optimised geometries of MP2/6-31G(d). Vibrational analysis from the second derivative Hessian matrix was performed 
for all the optimized structures to determine the nature of the stationary points. The first order saddle points were identified by the presence of one imaginary eigenvalue in the matrix while the local minima have all positive eigenvalues. Potential energy surfaces were plotted with respect to the relative energies to the sum of the energies of individual molecules.

The global electrophilicity index $(\omega)$ is calculated using the equation, $\omega=\left(\mu^{2} / 2 \eta\right)$ [54]. The chemical hardness $(\eta)$ and the electronic chemical potential $(\mu)$ quantities may be approached in terms of the one electron energies of Highest Occupied Molecular Orbital (HOMO) and Lowest Unoccupied Molecular Orbital (LUMO), $\varepsilon_{\mathrm{HOMO}}$ and $\varepsilon_{\mathrm{LUMO}}$, as $\eta \approx \varepsilon_{\mathrm{LUMO}}-\varepsilon_{\mathrm{HOMO}}$ and $\mu \approx\left(\varepsilon_{\mathrm{HOMO}}+\varepsilon_{\mathrm{LOMO}}\right) / 2$, respectively [55-56]. The relative nucleophilicity index $(\mathrm{N})$ is obtained based on the energies of HOMO within the scheme of Kohn-Sham [57]. This quantity can be defined as $\mathrm{N}=\mathrm{E}_{\mathrm{HOMO}(\mathrm{Nu})}-\mathrm{E}_{\mathrm{HOMO}}$ (TCE). As reference, we chose $\mathrm{TCE}$ (tetracyanoethylene) due to its lowest HOMO energy [58].

The Parr electrophilic $\left(P_{K}^{+}\right)$and Parr nucleophilic $\left(P_{K}^{-}\right)$functions [59], which enable characterisation of the electrophilic and nucleophilic centres of a molecule were obtained by the analysis of the Mulliken atomic spin density of the radical anion and the radical cation, respectively, of the molecule studied.

\section{Results and discussion}

\section{Mechanism of 32CA between nitrone and $\alpha, \beta$-unsaturated selenoaldehyde}

The mechanism of 32CA of nitrone (R1) and of $\alpha, \beta$-unsaturated selenoaldehyde (R2) was studied using ab initio method at MP2/6-31G(d). Scheme 1 shows the possible reaction pathways that can be undergone in this reaction between the two species. As shown, the reaction can undergo four regioisomeric reaction paths to form four different products. The first two pathways are the typical 32CA between nitrone and the alkene moiety of the substrate. The third and fourth pathways, on the other hand, involves 32CA with the selenoaldehyde part of the reactant.

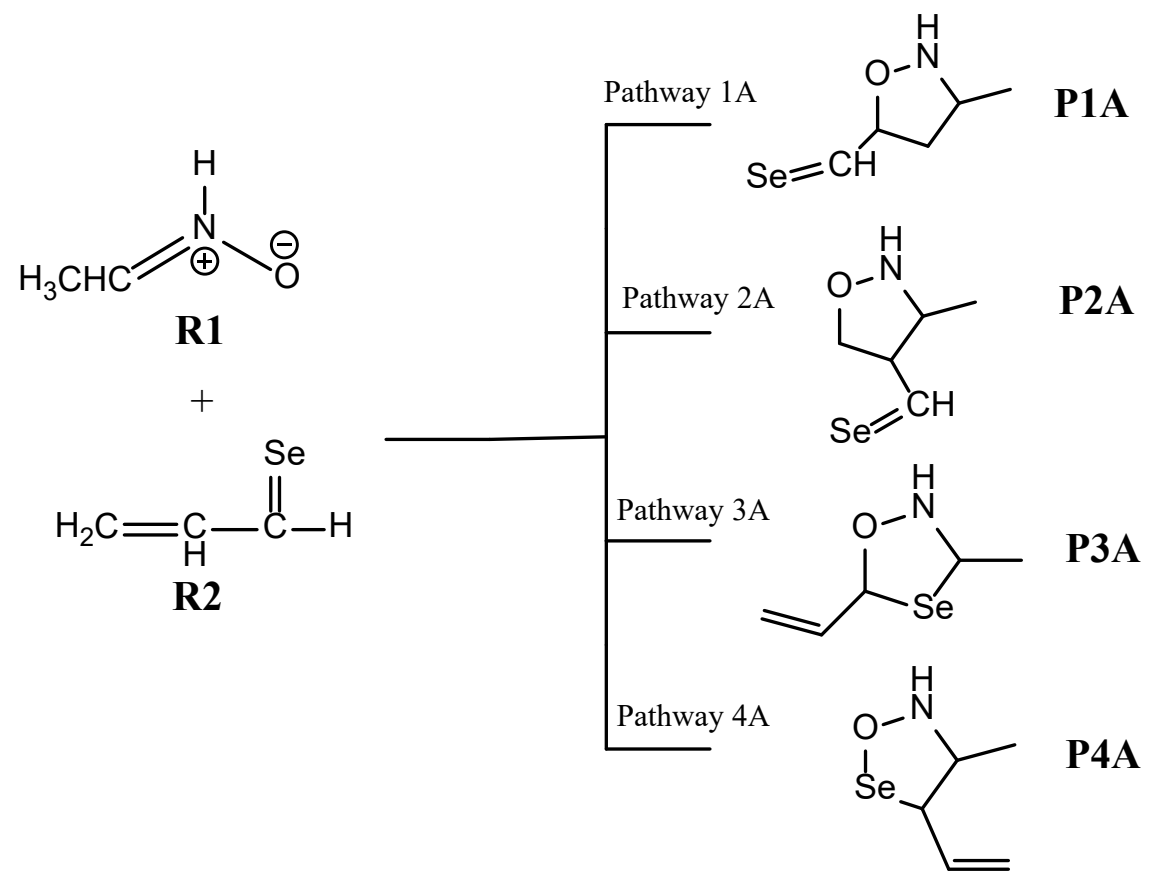

Scheme 1. The possible pathways for the reaction of 32CA of nitrone and $\alpha, \beta$-unsaturated selenoaldehyde. 
Fig. 1 shows the potential energy surface generated from plotting all the stationary points involved in the mechanism. The optimized structures and the key geometric parameters are presented as shown in Fig. 2. As shown in Scheme 1, pathway 1A involves the 32CA to produce a five-membered heterocyclic product, P1A, through the formation of $\mathrm{O}-\mathrm{C}$ and $\mathrm{C}-\mathrm{C}$ bonds. This pathway starts with the interaction between the two substrates in the appropriate orientation for the reaction to occur and it is an exothermic reaction of $29.36 \mathrm{~kJ} / \mathrm{mol}$ to form a molecular complex, INT1A.

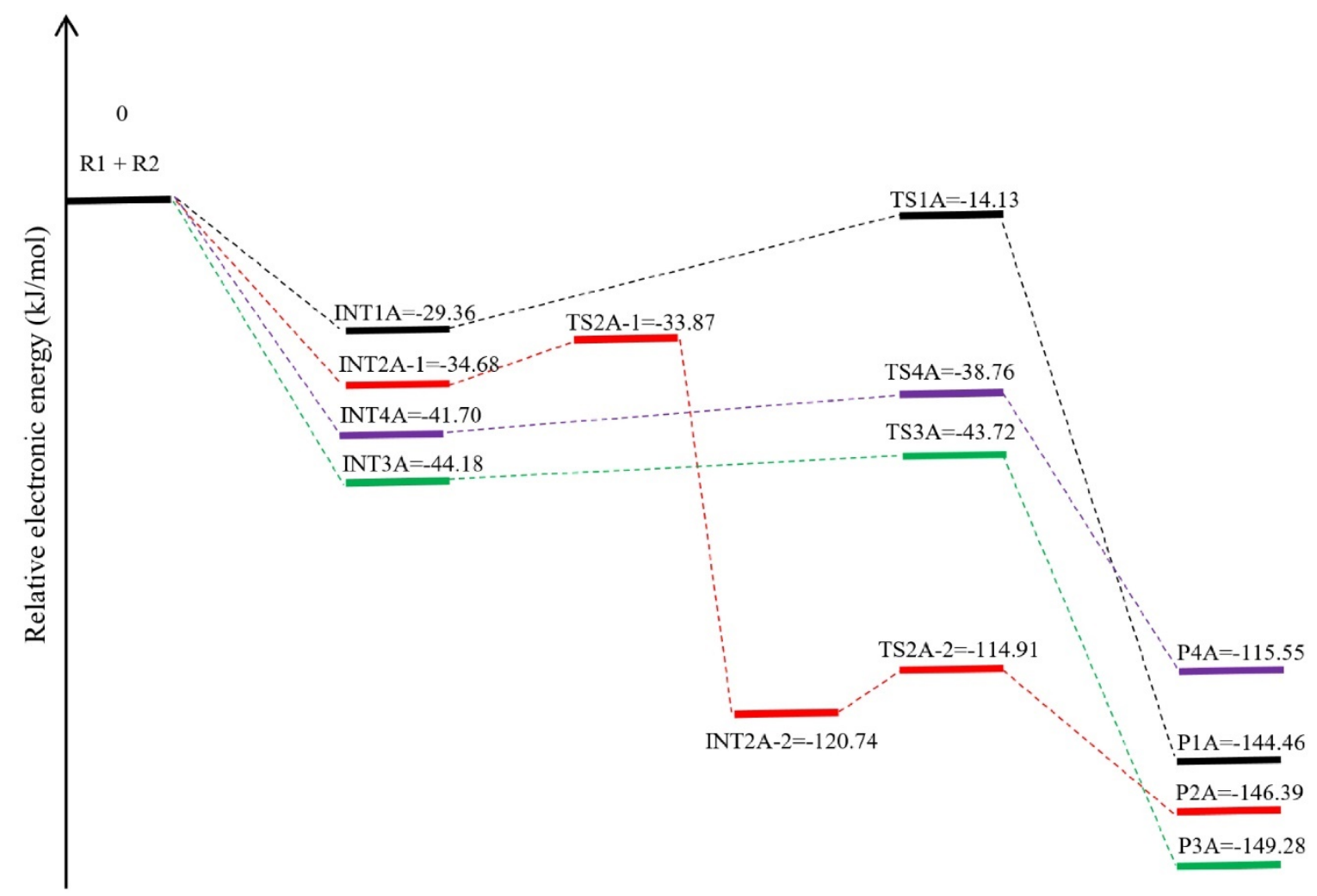

Fig. 1. Potential energy surface of the $32 \mathrm{CA}$ reaction mechanism of nitrone (R1) and $\alpha, \beta$-unsaturated selenoaldehyde ( R2). Relative energies are in unit kJ/mol. 


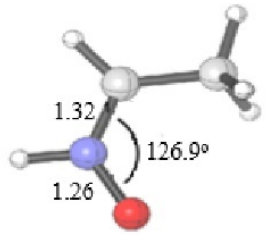

R1

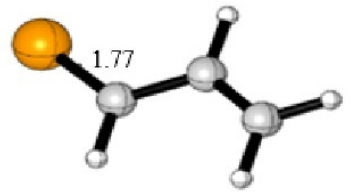

R2
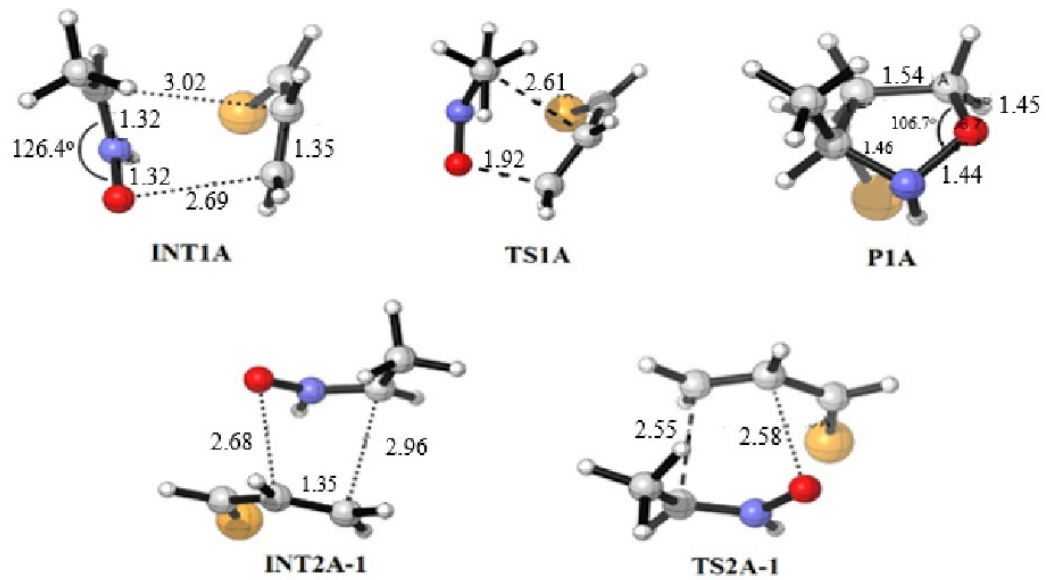

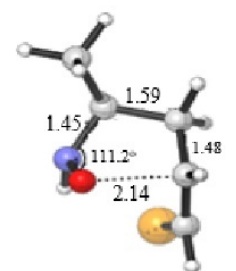

INT2A-2

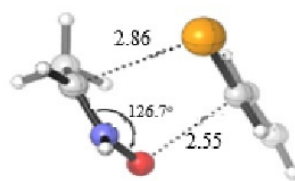

INT3A

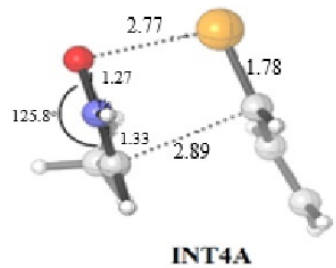

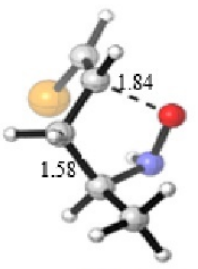

TS2A-2

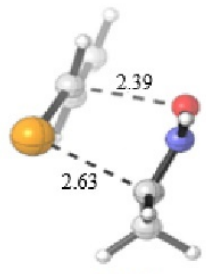

TS3A

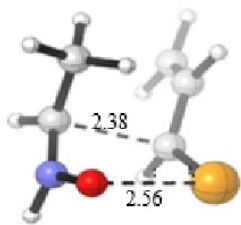

TS4A

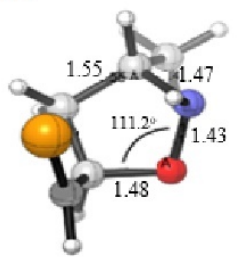

P2A

Fig. 2. The optimized geometries and the key parameters of all the stationary points found in the energy profile for 32CA of nitrone and $\alpha, \beta$-unsaturated selenoaldehyde (the bond length is given in $\AA$ ).

The reaction proceeds with the formation of a transition state, TS1A, which has an activation barrier of $15.23 \mathrm{~kJ} / \mathrm{mol}$. Following the intrinsic reaction channel, the pathway proceeds energetically downward by 
$130.33 \mathrm{~kJ} / \mathrm{mol}$ to the product well. As can be seen, the pathway is a one-step reaction involving electron transfers between the two reactants.

Pathway 2A leads to the formation of a similar heterocyclic product to P1A, with the carbonyl group as the side chain. This product, $\mathrm{P} 2 \mathrm{~A}$, is also produced via the formation of $\mathrm{O}-\mathrm{C}$ and $\mathrm{C}-\mathrm{C}$ bonds but in a different orientation compared to P1A. The transition state that leads directly to the product was not located. Therefore, this pathway was predicted to be a two-step reaction. The first step involves the formation of C-C bond between the two reactants which is $34.68 \mathrm{~kJ} / \mathrm{mol}$ exothermic in nature to produce INT2A-1. The pathway then leads to the formation of a transition state, TS2A-1, that $0.81 \mathrm{~kJ} / \mathrm{mol}$ higher in energy compared to INT2A-1. Following the intrinsic reaction channel, the reaction goes energetically downward by $86.87 \mathrm{~kJ} / \mathrm{mol}$ to form the product, INT2A-2. The following step involves the formation of O-C bond with the second transition state, TS2A-2, at an activation barrier of $5.83 \mathrm{~kJ} / \mathrm{mol}$. Following the intrinsic reaction channel, the pathway goes energetically downward by $31.48 \mathrm{~kJ} / \mathrm{mol}$ to the formation of product P2A. The formation of the two bonds to form the heterocyclic product occurs in two steps instead of a single step, as seen in pathway 1.

The entitled unsaturated selenoaldehyde has two double bonding regions. Nitrone can react with it at both positions and in different orientations. Pathway 1A and 2A describe the reaction at the alkene moiety of selenoaldehyde but in two different orientations. Here forth, the two other pathways in which the reactants undergo are described. Pathway $3 \mathrm{~A}$ is a one-step reaction, producing five-membered heterocyclic product, P3A, with the vinyl group at the side chain. The pathway is initiated with an interaction between the two reactants in the right orientation for the reaction to occur. This interaction produces an intermediate, INT3A, which is $44.18 \mathrm{~kJ} / \mathrm{mol}$ relative to the sum of energies of the two reactants. The pathway then proceeds with the formation of TS3A with an activation barrier of $0.46 \mathrm{~kJ} / \mathrm{mol}$. The computed intrinsic reaction channel leads energetically downward by $105.56 \mathrm{~kJ} / \mathrm{mol}$ to form P3A. The overall cycloaddition involves the formation of C-Se and C-O bonds.

Pathway 4A, on the other hand, is very similar to Pathway 3A but differ only in the orientation in which the two substrates react. In this case, the product, $\mathrm{P} 4 \mathrm{~A}$, is produced via the formation of O-Se and C-C bonds. The pathway starts with the two reactants interact in the appropriate orientation for the reaction to occur and this step is energetically favourable by $41.70 \mathrm{~kJ} / \mathrm{mol}$. Next, the pathway leads to the formation of a transition state that resides on top of a $2.94 \mathrm{~kJ} / \mathrm{mol}$ energy barrier. Following the intrinsic reaction channel, the pathway proceeds energetically downward of $76.79 \mathrm{~kJ} / \mathrm{mol}$ to form P4A. Overall, the pathway is a one-step reaction involving electron transfers between the selenium-analogue carbonyl group and nitrone.

This conclusion was supported by the calculated relative thermodynamic parameters obtained at MP2/6-31G(d) level, namely, heat of formation, $\Delta \mathrm{H}$, Gibbs free energy, $\Delta \mathrm{G}$, and entropy, $\Delta \mathrm{S}$, as shown in Table 1. Pathway $3 \mathrm{~A}$ has shown the lowest relative values of $\Delta \mathrm{H}$ and $\Delta \mathrm{G}$. The table also contains single point calculations relative to reactants $\left(E_{R}\right)$ at $M P 3 / 6-31 G(d)$ level of theory.

Table 1. Relative thermodynamic parameters $(\Delta \mathrm{H}, \Delta \mathrm{S}$ and $\Delta \mathrm{G})$ of the reaction, in $\mathrm{kJ} / \mathrm{mol}$, at the stationary points in the energy profile diagram relative to $\mathrm{R} 1$ and $\mathrm{R} 2$.

\begin{tabular}{|c|c|c|c|c|c|}
\hline & $\mathbf{E}_{\mathbf{R}} \mathbf{( k J / m o l )}$ & $\mathbf{E}_{\mathbf{R}}(\mathbf{k J} / \mathbf{m o l})$ & $\Delta \mathbf{H}$ & $\Delta \mathbf{G}$ & $\Delta \mathbf{S}$ \\
$\mathbf{M P 2} \mathbf{6 - 3 1 G}(\mathbf{d})$ & $\mathbf{M P 3 / 6 - 3 1 G ( d )}$ & $(\mathbf{k J / m o l})$ & $\begin{array}{c}\Delta \mathbf{k J / m o l}) \\
(\mathbf{k J} / \mathbf{m o l . K})\end{array}$ \\
\hline R1+ R2 & 0.00 & 0.00 & 0.00 & 0.00 & 0.00 \\
\hline INT1A & -34.15 & -94.25 & -24.12 & 16.35 & -0.14 \\
\hline TS1A & -14.29 & -62.64 & -9.70 & 49.12 & -0.20 \\
\hline P1A & -130.68 & -225.30 & -129.13 & -67.28 & -0.21 \\
\hline INT2A-1 & -38.07 & -90.71 & -29.18 & 16.60 & -0.15 \\
\hline TS2A-1 & -35.33 & -76.36 & -30.11 & 26.72 & -0.19 \\
\hline INT2A-2 & -112.52 & -133.56 & -110.78 & -46.76 & -0.21 \\
\hline TS2A-2 & -107.88 & -151.39 & -107.51 & -41.33 & -0.22 \\
\hline P2A & -133.02 & -226.13 & -131.63 & -69.80 & -0.21 \\
\hline INT3A & -40.60 & -96.30 & -38.35 & 8.92 & -0.16 \\
\hline TS3A & -46.11 & -86.45 & -40.28 & 14.96 & -0.19 \\
\hline P3A & -141.90 & -236.30 & -138.90 & -79.00 & -0.20 \\
\hline
\end{tabular}




\begin{tabular}{|c|c|c|c|c|c|}
\hline INT4A & -40.14 & -94.40 & -36.53 & 10.33 & -0.16 \\
\hline TS4A & -40.40 & -71.03 & -35.13 & 21.81 & -0.19 \\
\hline P4A & -108.36 & -197.59 & -149.32 & -89.95 & -0.22 \\
\hline
\end{tabular}

\section{Mechanism of 32CA between nitrile oxide and $\alpha, \beta$-unsaturated selenoaldehyde}

The mechanism of 32CA of nitrile oxide (R3) and $\alpha, \beta$-unsaturated selenoaldehyde (R2) was studied using ab initio method at MP2/6-31G(d). Scheme 2 shows the possible reaction pathways for the reaction between the two substrates. Similar to the reaction between nitrone and $\alpha, \beta$-unsaturated selenoaldehyde, there are four possible regioisomeric reaction paths producing four five-membered heterocyclic products. Pathways $1 \mathrm{~B}$ and $2 \mathrm{~B}$ demonstrate the $32 \mathrm{CA}$ between the nitrile oxide and the alkene moiety of $\alpha, \beta$-unsaturated selenoaldehyde. On the other hand, Pathways $3 \mathrm{~B}$ and $4 \mathrm{~B}$ show the $32 \mathrm{CA}$ between nitrile oxide and the selenoaldehyde moiety in R2.

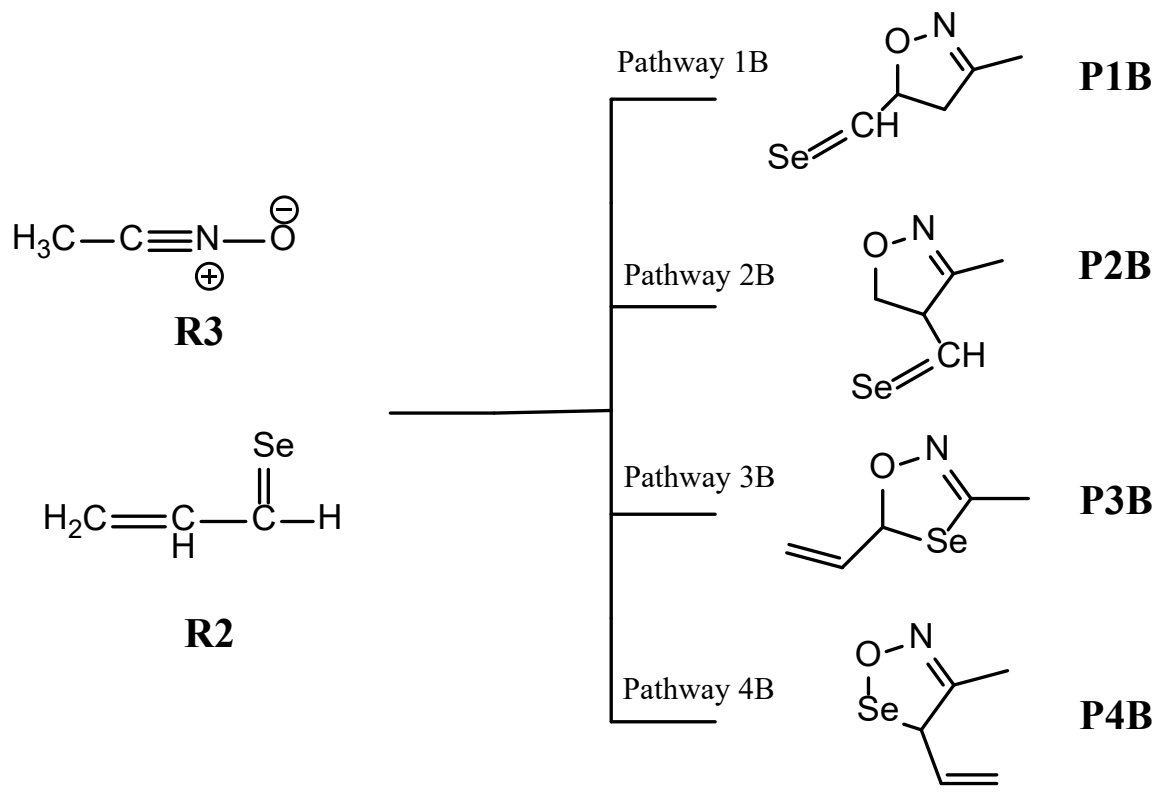

Scheme 2. The possible pathways for the reaction of 32CA of nitrile oxide and $\alpha, \beta$-unsaturated selenoaldehyde.

Fig. 3 shows the potential energy surface generated from plotting all the stationary points involved in the mechanism. The optimized structures and the key geometric parameters are presented as shown in Fig. 4. Pathway $1 \mathrm{~B}$ is a one-step 32CA reaction which produces a five-membered heterocyclic product, $\mathrm{P} 1 \mathrm{~B}$, via the formation of $\mathrm{O}-\mathrm{C}$ and $\mathrm{C}-\mathrm{C}$ bonds. The reactants interact with each other in an appropriate orientation for the reaction to occur and this step is energetically favourable by $23.81 \mathrm{~kJ} / \mathrm{mol}$ to form a molecular complex, INT1B. The reaction proceeds with the formation of a transition state, TS1B, which has an activation energy of 46.82 $\mathrm{kJ} / \mathrm{mol}$. 


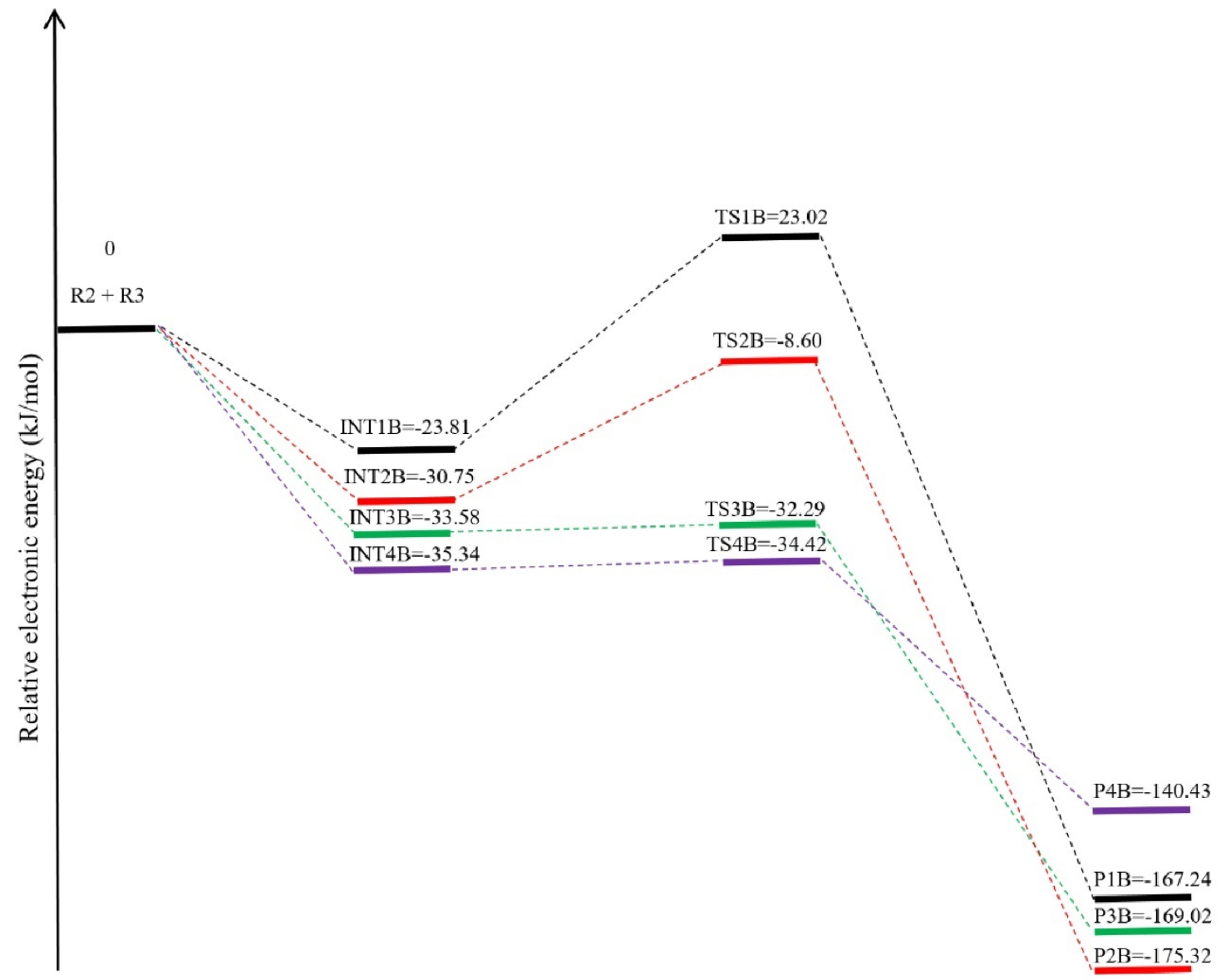

Fig. 3. Potential energy surface of the 32CA reaction mechanism of nitrone (R1) and $\alpha, \beta$-unsaturated selenoaldehyde (R2). Relative energies are in unit $\mathrm{kJ} / \mathrm{mol}$. 


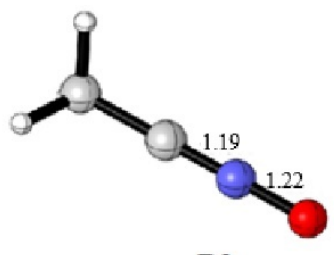

R3

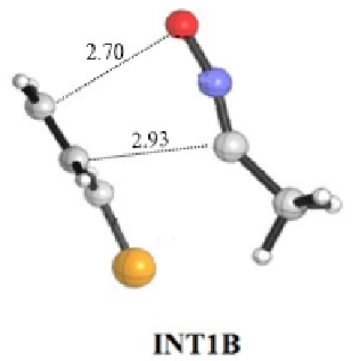

INT1B

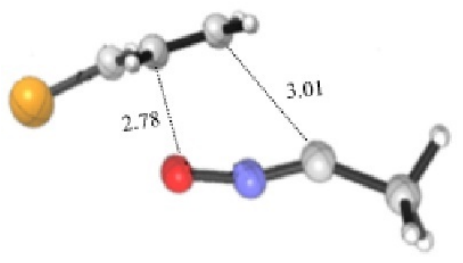

INT2B

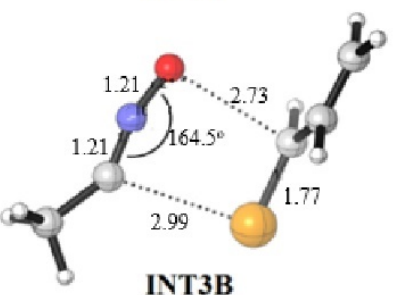

INT3B

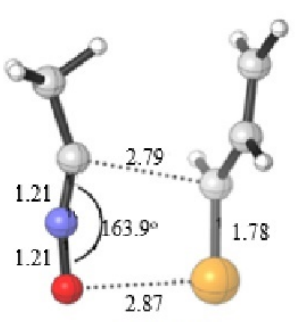

INT4B

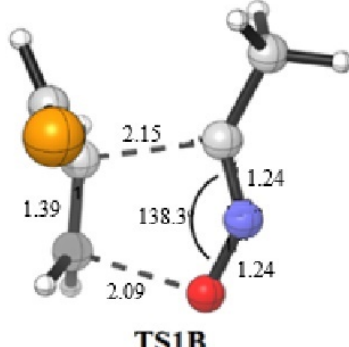

TS1B

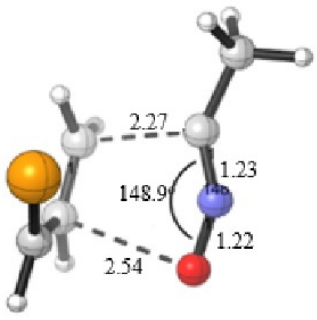

TS2B
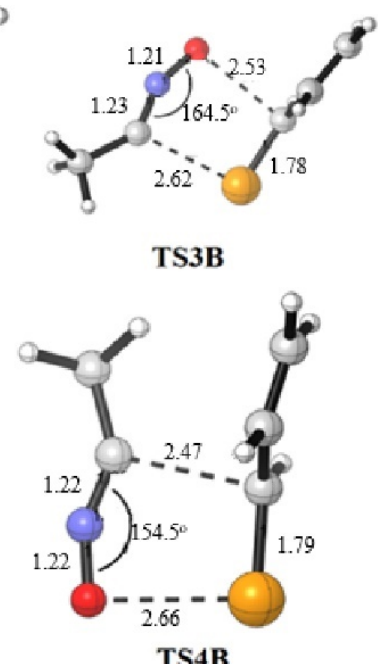

TS4B

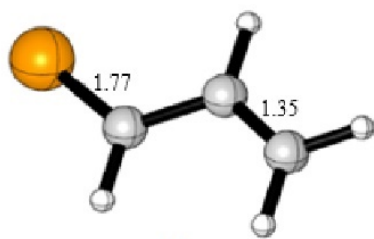

R2
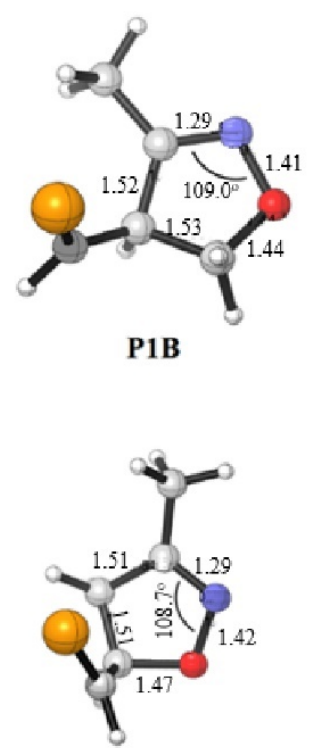

P2B
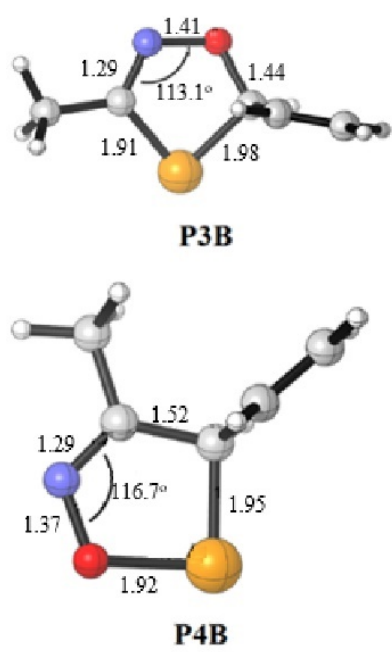

Fig. 4. The optimized geometries and the key parameters of all the stationary points found in the energy profile for 32CA of nitrile oxide and $\alpha, \beta$-unsaturated selenoaldehyde (the bond length is given in $\AA$ ). 
Following the intrinsic reaction channel, the pathway proceeds energetically downward by 190.26 $\mathrm{kJ} / \mathrm{mol}$ to form the product, P1B. The C-N bond in nitrile oxide elongates throughout the reaction and finally forming a double bond in the heterocyclic product.

Pathway 2B involves a 32CA that leads to the formation of the unsaturated heterocyclic product, P2B. The pathway starts with the interaction between the two reactants and is energetically favourable by 30.75 $\mathrm{kJ} / \mathrm{mol}$ to form an intermediate INT2B. The next step is the formation of transition state, TS2B that requires an activation energy of $22.15 \mathrm{~kJ} / \mathrm{mol}$. From the computed intrinsic reaction channel, the pathway proceed energetically downward by $166.72 \mathrm{~kJ} / \mathrm{mol}$ to the product well in the potential energy profile. Again, this pathway is a one-step reaction, very similar to pathway $1 \mathrm{~B}$ but differ only in terms of the orientation in which the reactants react.

The entitled unsaturated selenoaldehyde has two double bonding regions which can undergo 32CA with nitrile oxide. Pathways $1 \mathrm{~B}$ and $2 \mathrm{~B}$ demonstrate the cycloaddition at the alkene moiety of selenoaldehyde. As for Pathway 3B and 4B as shown in Scheme 2, the cycloaddition occurs at the C-Se double bond in the compound. Pathway 3B is a one-step reaction which produces the five-membered heterocyclic product, P3B, with vinyl group at the side chain. The reaction starts with the interaction between the two substrates in the correct orientation to produce P3B. This step is energetically favourable by $33.58 \mathrm{~kJ} / \mathrm{mol}$, forming intermediate INT3B. Next, the pathway leads to a transition state, TS3B, which sits on top of a $1.29 \mathrm{~kJ} / \mathrm{mol}$ activation barrier. Following the intrinsic reaction channel, the pathway goes downward energetically by $136.73 \mathrm{~kJ} / \mathrm{mol}$ to form P3B.

Pathway 4B is similar to Pathway 3B but the reactants are in different orientation which results in the formation of product P4B. Pathway 4B is a one-step cycloaddition reaction which starts with R2 and R3 interacting in an appropriate orientation for the reaction to occur which is shown in the structure of intermediate INT4B. This step goes downward energetically by $35.34 \mathrm{~kJ} / \mathrm{mol}$. The pathway leads to an activation barrier of $0.92 \mathrm{~kJ} / \mathrm{mol}$ with TS4B as the transition state. Intrinsic reaction channel shows that the reaction leads to an energetically downward pathway by $106.01 \mathrm{~kJ} / \mathrm{mol}$ to form the product, P4B. The relative thermodynamic parameters of all the transition states, reactants, products and reaction molecular complex at MP2/6-31G(d) level are listed in Table 2. The table also contains single point calculations relative to reactants at MP3/6-31G(d) level of theory.

Table 2. Relative thermodynamic parameters $(\Delta \mathrm{H}, \Delta \mathrm{S}$ and $\Delta \mathrm{G})$ of the reaction, in $\mathrm{kJ} / \mathrm{mol}$, at the stationary points in the energy profile diagram relative to R3 and R2.

\begin{tabular}{|c|c|c|c|c|c|}
\hline & $\begin{array}{c}E_{R}(\mathrm{~kJ} / \mathrm{mol}) \\
M P 2 / 6-31 G(d)\end{array}$ & $\begin{array}{c}E_{R}(\mathrm{~kJ} / \mathrm{mol}) \\
\mathrm{MP3} / 6-31 \mathrm{G}(\mathrm{d})\end{array}$ & $\begin{array}{c}\Delta \mathbf{H} \\
(\mathrm{kJ} / \mathrm{mol})\end{array}$ & $\begin{array}{c}\Delta \mathbf{G} \\
(\mathrm{kJ} / \mathrm{mol})\end{array}$ & $\begin{array}{c}\Delta \mathrm{S} \\
(\mathrm{kJ} / \mathrm{mol} . \mathrm{K})\end{array}$ \\
\hline $\mathrm{R} 3+\mathrm{R} 2$ & 0.00 & 0.00 & 0.00 & 0.00 & 0.00 \\
\hline INT1B & -28.14 & -100.66 & -13.66 & 12.62 & -0.09 \\
\hline TS1B & 21.78 & -18.72 & 30.58 & 78.08 & -0.16 \\
\hline P1B & -150.72 & 50.62 & -149.96 & -95.43 & -0.18 \\
\hline INT2B & -34.25 & -83.74 & -21.02 & 12.48 & -0.11 \\
\hline TS2B & -10.10 & -36.84 & -0.77 & 44.53 & -0.15 \\
\hline P2B & -162.82 & 17.65 & -158.49 & -104.47 & -0.18 \\
\hline INT3B & -37.47 & -92.58 & -23.65 & 7.02 & -0.10 \\
\hline TS3B & -35.81 & -71.70 & -25.21 & 15.44 & -0.14 \\
\hline P3B & -160.11 & 50.79 & -156.01 & -103.61 & -0.18 \\
\hline INT4B & -38.79 & -88.38 & -25.78 & 9.97 & -0.12 \\
\hline TS4B & -37.29 & -68.80 & -27.53 & 17.71 & -0.15 \\
\hline P4B & -134.78 & 101.92 & -128.15 & -78.19 & -0.17 \\
\hline
\end{tabular}

\section{Theoretical analysis and evaluation of the most dominant reaction pathway}

According to the above results, it is clear that Pathway 3(A and B) and Pathway 4(A and B) are the two competing reaction channels. The activation barriers for the two pathways are shown to be relatively low 
compared to the activation barriers in other reaction pathways. The numerical value of the activation energies may not be entirely reliable for quantitative analysis since MP2 is known for overestimation of the interaction between two molecules. As a result of that, the energy of the transition state may be much lower than expected. However, qualitative analysis on the reaction channels provides an insight as to which reaction channel is more dominant and we believe that the analysis presented in this study is reliable for further investigation.

For the cycloaddition reaction between nitrone and selenoaldehyde, it was shown that Pathway $3 \mathrm{~A}$ and Pathway 4A are the two competing reaction channels due to the very low activation barriers in the pathway. The activation barriers of the two pathways are very low but Pathway 3A shows slightly lower activation energy compared to that in Pathway 4A. Since the two activation energies are so close in values, a conclusion cannot be made as to which reaction channel is more dominant. The orientation in which the substrates interact is important for the reaction as this is the only factor which distinguishes Pathway 3A and 4A. Having said that, looking at the energy profile more closely, it can be seen that the product, $\mathrm{P} 3 \mathrm{~A}$ is far more stable compared to product, P4A by $33.73 \mathrm{~kJ} / \mathrm{mol}$. Hence, we would expect that the reaction will most probably produce a mixture of products, with the composition of P3A to be higher than P4A. Along the reaction pathway for the two channels, the reactants undergo several structural changes to form the products. In Pathway $3 \mathrm{~A}$, the two reactants draw closer to each other as the reaction proceeds with the C-Se distances being $2.85 \AA$ (INT3A), 2.63 $\AA$ (TS3A) and $2.00 \AA$ (P3A) while the $\mathrm{O}-\mathrm{C}$ distances are $2.55 \AA$ (INT3A), $2.39 \AA$ (TS3A) and $1.44 \AA$ (P3A). Since the reaction forms a cyclic compound, the O-N-C bond angle in nitrone decreased when the product is formed, with it being $126.7^{\circ}$ (INT3A) and $106.4^{\circ}$ in P3A. Another change that was seen is the bond length of $\mathrm{C}$-Se in selenoaldehyde which elongates from $1.77 \AA$ (INT3A) to $2.00 \AA$ (P3A). In pathway $4 \mathrm{~A}$, the distances between the two reactants decreases, with O-Se distances are $2.77 \AA$ (INT4A), $2.56 \AA$ (TS4A) and $1.91 \AA$ (P4A) while the C-C distances are $3.10 \AA$ (INT4A), $2.38 \AA$ (TS4A) and $1.56 \AA$ (P4A). The reaction forms a heterocyclic compound, causing the O-N-C bond angle in nitrone to decrease when the product is formed, with it being $125.8^{\circ}$ (INT4A) and $106.4^{\circ}$ in P4A. The bond length of C-Se in selenoaldehyde elongates from $1.78 \AA$ (INT4A) to $1.97 \AA$ (P4A).

For the cycloaddition reaction between nitrile oxide and selenoaldehyde, it was shown that Pathway 3B and Pathway 4B are the two competing reaction channels due to the very low activation barriers in the pathway. The activation barriers of the two pathways are very low but Pathway 4B shows slightly lower activation energy compared to that in Pathway 3B. The same explanation applies for this reaction since the two activation energies are so close in values. From the energy profile, it can be seen that the product, $\mathrm{P} 3 \mathrm{~B}$ is more stable than product, $\mathrm{P} 4 \mathrm{~B}$ by $28.59 \mathrm{~kJ} / \mathrm{mol}$. Therefore, we expect that the reaction will most probably produce a mixture of products, with the composition of $\mathrm{P} 3 \mathrm{~B}$ to be higher than $\mathrm{P} 4 \mathrm{~B}$. The reactants undergo several structural changes along the reaction pathways. In Pathway 3B, the distances between the two reactants decrease as the reaction proceeds with the C-Se distances being $3.00 \AA$ (INT3B), $2.62 \AA$ (TS3B) and $1.91 \AA$ (P3B) while the O-C distances are $2.74 \AA$ (INT3B), $2.53 \AA$ (TS3B) and $1.44 \AA$ (P3B). The O-N-C bond angle in nitrone decreased when the product is formed to accommodate the heterocyclic structure, with it being $164.5^{\circ}$ (INT3B) and $113.1^{\circ}$ in P3B. Another change that was seen is the bond length of C-Se in selenoaldehyde which elongates from $1.77 \AA$ (INT3B) to $1.98 \AA$ (P3B). In pathway 4B, the distances between the two reactants decreases, with O-Se distances are $2.87 \AA$ (INT4B), $2.66 \AA$ (TS4B) and $1.92 \AA$ (P4B) while the C-C distances are $2.79 \AA$ (INT4B), $2.47 \AA$ (TS4B) and $1.52 \AA$ (P4B). The reaction forms a heterocyclic compound, causing the O-N-C bond angle in nitrone to decrease when the product is formed, with it being $163.9^{\circ}$ (INT4B) and $116.7^{\circ}$ in P4B. The bond length of C-Se in selenoaldehyde elongates from $1.78 \AA$ (INT4B) to $1.95 \AA$ (P4B).

\section{Analysis of the CDFT reactivity indices of nitrone, nitrile oxide and selenoaldehyde}

An analysis of the CDFT reactivity indices computed in gas phase at the $298 \mathrm{~K}$ of reactants was performed to predict their reactivity in cycloaddition reactions. The conceptual DTF indices including the chemical hardness $(\eta)$, the electronic chemical potential $(\mu)$, global electrophilicity index $(\omega)$ and the global nucleophilicity index $(\mathrm{N})$, in $\mathrm{eV}$, for each reactant are listed in Table 3.

The electronic chemical potential of $\mathrm{R} 1, \mu=-3.09, \mathrm{R} 3, \mu=-2.90$, is higher than that of $\mathrm{R} 2$, thereby indicating that the global electron density transfer will take place from R1 and R3 towards electron poor R2. The electrophilicity of R1 and R3 is 0.87 and $0.55 \mathrm{eV}$, respectively, which allow for the classification of these reactants as marginal electrophiles within the electrophilicity scale [60]. On the other hand, R2 is classified as 
a strong electrophile within the scale of electrophilicity. Moreover, R2 is also classified as a stronger nucleophile than the other within the nucleophilicity scale [61]. The electrophilicity difference, $\Delta \omega$, between the R1 and R2 is 2.38 , while $\Delta \omega$ between R3 and R2 is $2.70 \mathrm{eV}$, which has been suggested as a measure of the polar character of 32CA reactions, indicates that these reactions will have a large polar character.

In addition to the global indices, local electrophilicity/nucleophilicity descriptors such as the Parr functions are extensively used to explore the local reactivity and site selectivity, especially in cycloaddition reactions [59-62]. The Parr electrophilic $P_{K}^{+}$and Parr nucleophilic $P_{K}^{-}$functions at the atoms of R1, R2 and R3 are given in Table 4. An analysis of Parr functions found that the carbon atom $\mathrm{C} 3$ is the most electrophilic center with, $P_{K}^{+}=0.45$ and 0.31 in R1 and R3, respectively, while $\mathrm{C} 1$ and $\mathrm{C} 3$ is the most electrophilic center with, $P_{K}^{+}=0.46$ in R2. However, the nucleophilic $P_{K}^{-}$Parr functions at the oxygen atom $\mathrm{O} 1$ is the most nucleophilic center with a value, $P_{K}^{-}=0.71$ and 0.69 for the reactants R1 and R3, respectively, while Se4 is the most nucleophilic center with a value, $P_{K}^{-}=1.05$ for the R3.

Table 3. B3LYP/6-31G(d) electronic chemical potential $(\mu)$, chemical hardness $(\eta)$, electrophilicity $(\omega)$ and nucleophilicity $(\mathrm{N})$, in $\mathrm{eV}$, of reactants.

\begin{tabular}{|c|c|c|c|c|}
\hline & $\boldsymbol{\eta}$ & $\boldsymbol{\mu}$ & $\boldsymbol{\omega}$ & $\mathbf{N}$ \\
\hline R1 & 5.45 & -3.09 & 0.87 & 3.31 \\
\hline R2 & 2.84 & -4.29 & 3.25 & 3.41 \\
\hline R3 & 7.66 & -2.90 & 0.55 & 2.40 \\
\hline
\end{tabular}

Table 4. The Parr electrophilic $P_{K}^{+}$and Parr nucleophilic $P_{K}^{-}$functions at the atoms of R1, R2 and R3 at B3LYP/6-31G(d) level of theory.

\begin{tabular}{|c|c|c|c|c|}
\hline Reactant & Structure & $\operatorname{Atom}(n)$ & $P_{K}^{-}$ & $P_{K}^{+}$ \\
\hline \multirow[b]{2}{*}{ R1 } & & $\mathrm{C} 3$ & 0.32 & 0.45 \\
\hline & & $\mathrm{O} 1$ & 0.71 & 0.19 \\
\hline \multirow{4}{*}{ R2 } & & $\mathrm{C} 1$ & -0.06 & 0.46 \\
\hline & & $\mathrm{C} 2$ & 0.05 & -0.13 \\
\hline & & $\mathrm{C} 3$ & -0.08 & 0.46 \\
\hline & HE & $\mathrm{Se} 4$ & 1.05 & 0.28 \\
\hline \multirow[b]{2}{*}{$\mathbf{R 3}$} & & $\mathrm{C} 3$ & 0.3 & 0.31 \\
\hline & & $\mathrm{O} 1$ & 0.69 & 0.09 \\
\hline
\end{tabular}




\section{ELF topological analysis of the electronic structure of R1, R2 and R3}

The reactivity of nitrone can be correlated with their electronic structure. Therefore, an ELF topological analysis of the nitrone and methacrylonitrile was performed in order to characterize the electronic structure of this three-atom-component (TAC). The representation and attractor positions of ELF valence basins, as well as ELF electron populations, arising from the ELF topological analysis are shown in Fig. 5.

ELF topology of the nitrone permits establishing the electronic structure distribution on this TAC (see Fig. 5). However, nitrone presents two $\mathrm{V}(\mathrm{O})$ and $\mathrm{V}^{\prime}(\mathrm{O})$ monosynaptic basins, integrating $2.87 \mathrm{e}$ and $3.04 \mathrm{e}$ (total $5.91 \mathrm{e})$, and one $\mathrm{V}(\mathrm{O}, \mathrm{N})$ disynaptic basin with a population of $1.32 \mathrm{e}$. This behavior suggests that the O-N bonding region is strongly polarized towards the $\mathrm{O}$ oxygen atom. Additionally, the presence of one $\mathrm{V}(\mathrm{N}, \mathrm{C})$ disynaptic basin integrating 3.99e indicates that the $\mathrm{N}-\mathrm{C}$ bonding region has a strong double bond character. Consequently, ELF topology of the nitrone clearly indicates that this TAC is able to participate only in zw-type 32CA reactions, as it neither presents a pseudodiradical electronic structure [63], and thus, ELF topological allows establishing the proposed Lewis structure given in Fig. 6. On the other hand, the ELF topology of selenoaldehyde shows the presence of two $\mathrm{V}(\mathrm{Se})$ and $\mathrm{V}^{\prime}(\mathrm{Se})$ monosynaptic basins, integrating $2.78 \mathrm{e}$ and $2.70 \mathrm{e}$ (total $5.48 \mathrm{e}$ ), and one $\mathrm{V}(\mathrm{Se}, \mathrm{C})$ disynaptic basin with a population of $2.48 \mathrm{e}$. The $\mathrm{R} 2$ also presences one $\mathrm{V}(\mathrm{C}, \mathrm{C})$ disynaptic basin integrating a total electronic density of $3.29 \mathrm{e}$ indicates that the $\mathrm{C}-\mathrm{C}$ bonding region has a strong double bond character.

Nitrile oxides are linear propargylic TACs, which have a zwitterionic structure participating in $z w$-type [64]. An ELF topological analysis of nitrile oxide R3 shows the presence of a $V(O)$ basins integrating a total population of 5.73e indicating the presence of three lone pairs of electrons. The $\mathrm{R} 3$ has one $\mathrm{V}(\mathrm{O}, \mathrm{N})$ disynaptic basin with a population of $1.52 \mathrm{e}$. Furthermore, the presence of $\mathrm{V}(\mathrm{N}, \mathrm{C})$ disynaptic basin integrating $6.27 \mathrm{e}$ indicates that the $\mathrm{N}-\mathrm{C}$ bonding region has a strong triple bond character. Therefore, ELF topology of the nitrone clearly indicates that this TAC is able to participate only in zw-type 32CA reactions, as it neither presents a pseudodiradical electronic structure and thus, ELF topological allows establishing the proposed Lewis structure given in Fig. 6.
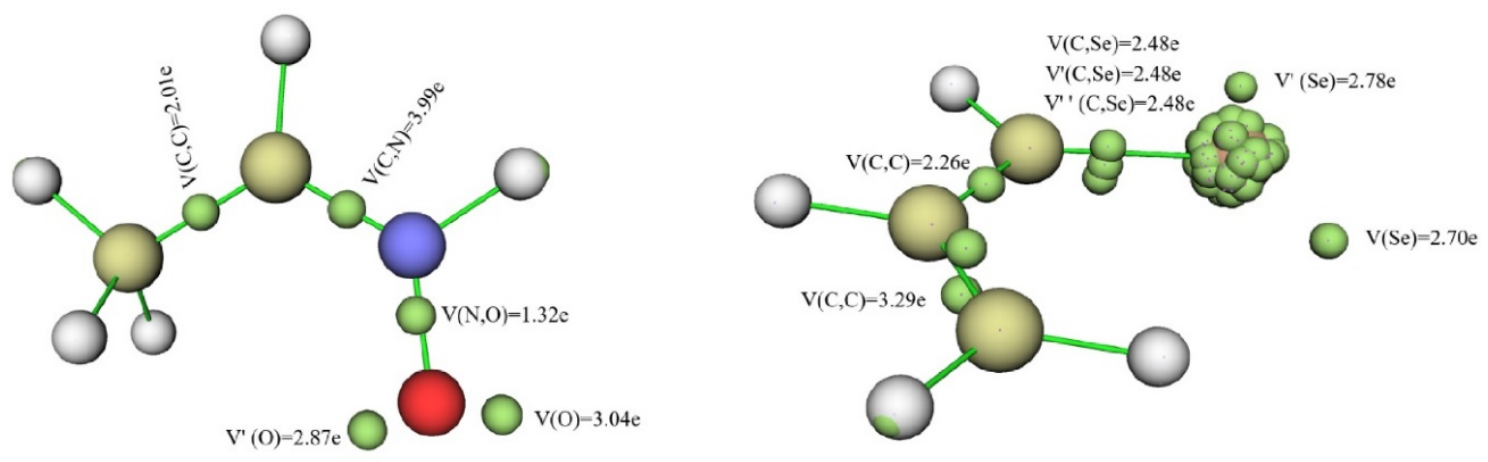

R1

$\mathbf{R 2}$

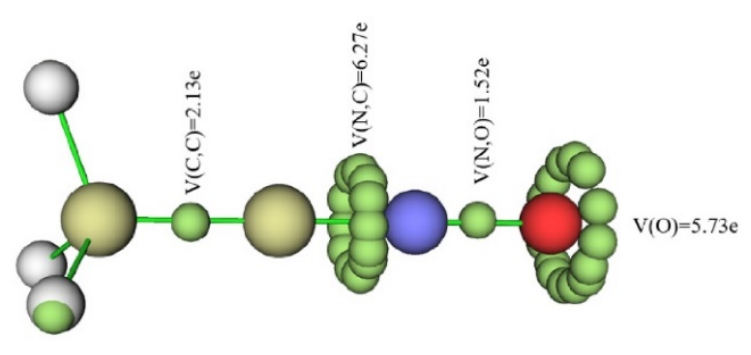

R3

Fig. 5. ELF valence basins populations, in e, of R1, R2 and R3. 


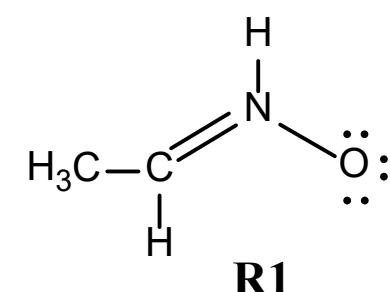<smiles>C=CC=[Se]</smiles>

R2

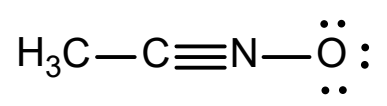

R3

Fig. 6. Representation of Lewis structures for nitrone, nitrile oxide and selenoaldehyde obtained from ELF topological analysis in zwitterionic-type.

To study the molecular mechanism of the 32CA reaction of R1 with R2 and R3 with R2, the ELF analysis of the more favorable transition states, TS3A, TS4A, TS3B and TS4B, was performed. In this way, the variation of the electron density between interacting atoms was evaluated to display the bond formation pattern and the molecular mechanism of the reaction. The ELF valence attractor positions and their corresponding populations are given in Fig. 7.

At all transition states, new $\mathrm{V}(\mathrm{C})$ monosynaptic basins are appeared with a population of $0.43 \mathrm{e}, 0.35 \mathrm{e}$, $0.41 \mathrm{e}$ and $0.77 \mathrm{e}$ for TS3A, TS4A, TS3B and TS4B, respectively, resulting from depopulation of $\mathrm{V}(\mathrm{C}, \mathrm{N})$ disynaptic basins (see ELF of R1 and R3 in Fig. 5). Also, new V(N) monosynaptic basins are created on the nitrogen atom with population of $0.86 \mathrm{e}, 1.12 \mathrm{e}, 1.45 \mathrm{e}$ and $1.68 \mathrm{e}$ for TS3A, TS4A, TS3B and TS4B, respectively, which indicating the appearance of a nonbonding electron pair on the $\mathrm{N}$ atom in each transition state. 


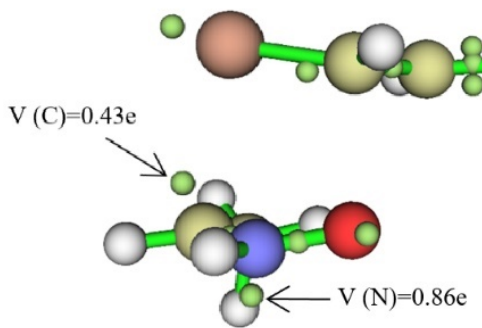

TS3A

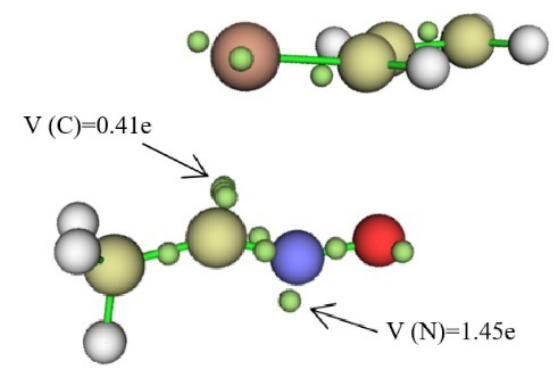

TS3B

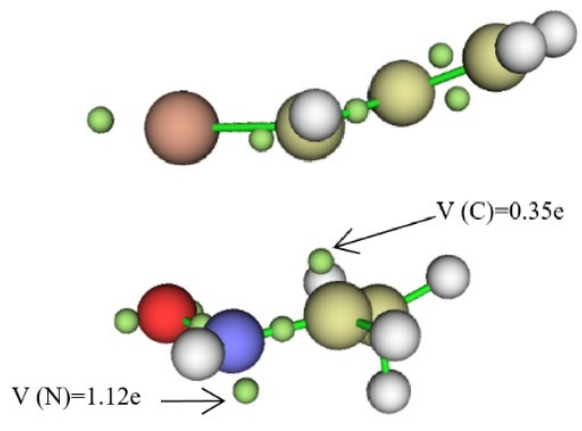

TS4A

O
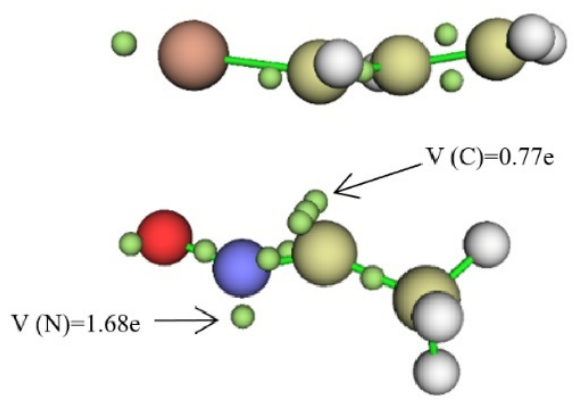

TS4B

Fig. 7. ELF valence attractor positions and the corresponding populations for the most favorable transition states (TS3A, TS4A, TS3B and TS4B).

The molecular electrostatic potential (MESP) map of the transition states were computed in order to display the charge transfer in a comparable manner. Fig. 8 illustrates the MESP maps for transition states TS3A, TS4A, TS3B and TS4B of two competitive pathways Pathway 3A, Pathway 4A, Pathway 3B and Pathway 4B, respectively. In the MESP map, the red and blue colors indicate the region with higher and lower electron density, respectively.

It is clear from Fig. 3 that at the energetically more favorable transition state, TS3A, approach of reactants locates the oppositely charged regions over each other resulting in attractive forces between two fragments. On the other hand, at the energetically less favorable transition state, TS4A, regions with the same charge are forced to be located over each other leading to repulsive forces between two fragments. Therefore, due to the electrostatic attractive forces between two interacting fragments, formation of TS3A is more favorable than formation of TS4A. Similarly, according to the MESP map, formation of TS3B is more favorable than the formation of TS4B, while TS4B is energetically more preferable than TS3B by $2.13 \mathrm{~kJ} / \mathrm{mol}$. 


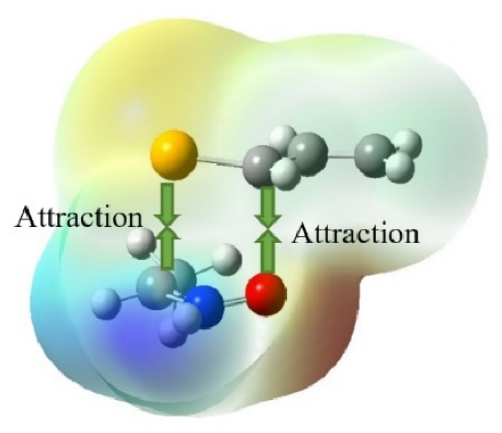

TS3A

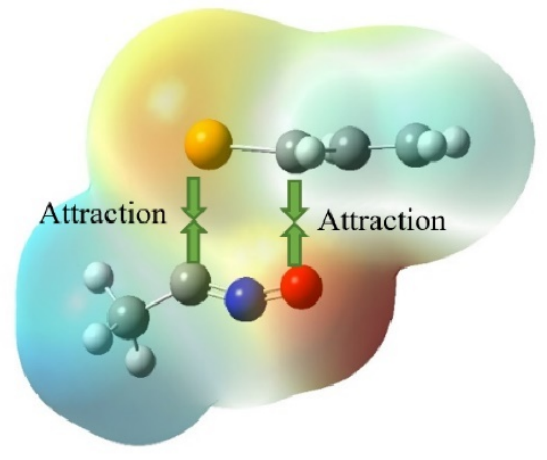

TS3B

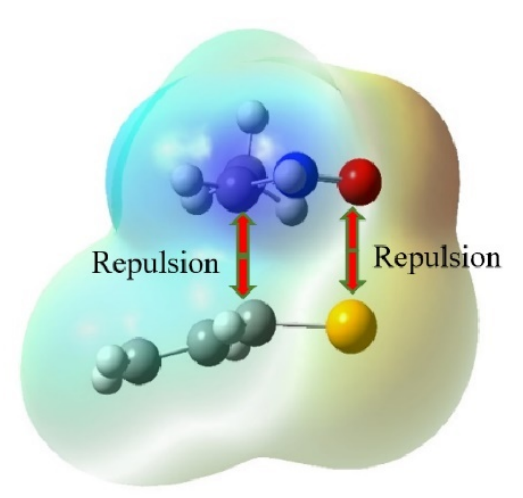

TS4A

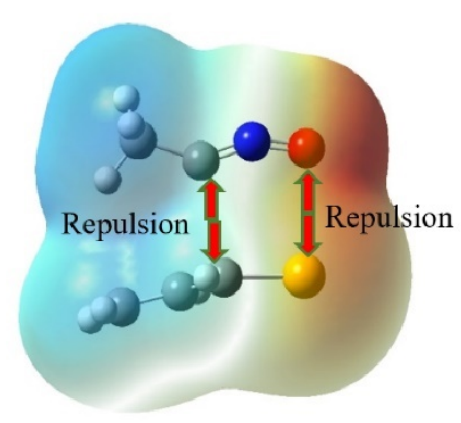

TS4B

Fig. 8. The molecular electrostatic potential (MEP) maps of the most favorable transition states (TS3A, TS4A, TS3B and TS4B).

\section{Conclusion}

The 32CA reactions between $\alpha, \beta$-unsaturated selenoaldehyde with nitrone and also with nitrile oxide have been investigated at MP2/6-31G(d) level of theory. The reaction mechanisms are reported and the potential energy surfaces are plotted with respect to the energies of the stationary points. The competing pathways in both reactions are Pathway 3 and Pathway 4 but it is expected that Pathway 3 would be more dominant due to the formation of a more stable product. Analysis on the dominant reaction channels reveals that the cycloaddition reactions are more likely to occur at the carbonyl group with selenium atom rather than the alkene moiety. Analysis of conceptual DFT reactive indices of the reactants accounts for the polar character of the studied reactions. Analysis of the electronic structure of nitrone and nitrile oxide and their participation in 32CA reactions towards selenoaldehyde allows establishing a useful classification of 32CA reactions into zw-type reactions involving TACs with a high zwitterionic character. 


\section{Acknowlegments}

Authors would like to thank their respective universities for their support. Gaussian09 was the only used calculation software in this study, with CI reference number: 57295 and Invoice number: ACI564467081250 .

\section{References}

1. Liu, K.C.; Howe, R.K. J. Org. Chem. 1983, 48, 4590-4592.

2. Lacy, C.; Scheuer, P. J. J. Nat. Prod. 2000, 63, 119-12.

3. Liu, S.; Fu, X.; Scheuer, F. J.; Kelly-Borges, P. J. J. Nat. Prod. 1997, 60, 614-615.

4. Ichiba, T.; Scheuer, P. J. J. Org. Chem. 1993, 58, 4149-4150.

5. Brandi, A.; Cicchi, S.; Cordero, F. M.; Goti, A. Chem. Rev. 2003, 103, 1213-1270.

6. Kanemasa, S.; Tsuge, O. Heterocycles 1990, 30, 719-736.

7. King, S. W.; Riordan, J. M.; Holt, E. M.; Stammer, C. H. J. Org. Chem. 1982, 47, 3270-3273.

8. Padwa, A. 1,3-Dipolar Cycloaddition Chemistry; Wiley: New York, 1984.

9. Gothelf, K. V.; Jørgensen, K. A. Chem. Rev. 1998, 98, 863-910.

10. Karlsson, S.; Högberg, H. E. Org. Prep. Proced. Int. 2001, 33, 103-172.

11. Pellissier, H. Tetrahedron 2007, 63, 3235-3285.

12. Confalone, P. N.; Huie, E. M. Org. React. 1988, 36, 1-173.

13. Black, D.; Crozier, R. F.; Davies, V. C. Synthesis 1975, 205-221.

14. Ding, P.; Miller, M.; Chen, Y.; Helquist, P.; Oliver, A. J.; Wiest, O. Org. Lett. 2004, 6, 1805-1808.

15. Wess, G.; Kramer, W.; Schubert, G.; Enhsen, A.; Baringhaus, K. H.; Globmik, H.; Müller, S.; Bock, K.; Klein, H.; John, M.; Neckermann, G.; Hoffmann, A. Tetrahedron Lett. 1993, 34, 819-822.

16. Padwa, A.; Pearson, W. H. Synthetic Applications of 1,3-Dipolar Cycloaddition Chemistry Toward Heterocycles and Natural Products; Wiley \& Sons: New York, 2002.

17. Zhao, H.; Li, X.; Ran, X.; Zhang, W. J. Mol. Struct. (Theochem) 2004, 683, 207-213.

18. Nacereddine, A. K.; Yahia, W.; Bouacha, S.; Djerourou, A. Tetrahedron Lett. 2010, 51, 2617-2621.

19. Dorostkar-Ahmadi, N.; Bakavoli, M.; Moeinpour, F.; Davoodnia, A. Spectrochim. Acta A 2011, 79 , 1375-1380.

20. Magnuson, E. C.; Pranata, J. J. Comput. Chem. 1998, 19, 1795-1804.

21. Cossío, F. P.; Morao, I.; Jiao, H.; Schleyer, P. J. Am. Chem. Soc. 1999, 121, 6737-6746.

22. Rastelli, A.; Gandolfi, R.; Sarzi-Amande, M.; Carboni, B. J. Org. Chem. 2001, 66, 2449-2458.

23. Di Valentin, C.; Freccero, M.; Gandolfi, R.; Rastelli, A. J. Org .Chem. 2000, 65, 6112-6120.

24. Domingo, L. R. Eur. J. Org. Chem. 2000, 2000, 2265-2272.

25. Carda, M.; Portolés, R.; Murga, J.; Uriel, S.; Marco, J. A.; Domingo, L. R.; Zaragozá, R. J.; Röper, H. Eur. J. Org. Chem. 2000, 65, 7000-7009.

26. Merino, P.; Revuelta, J.; Tejero, T.; Chiacchio, U.; Rescifina, A.; Romeo, G. Tetrahedron 2003, 59, 3581-5392.

27. Fleming, I. Frontiers Orbitals and Organic Chemical Reactions, Wiley, London, 1976.

28. Houk, K. N. Acc. Chem. Res. 1975, 8, 361-369.

29. Kang, K. H.; Pae, A. N.; Choi, K. I.; Cho, Y. S.; Chung, B. Y.; Lee, J. E.; Jung, S. H.; Koh, H. Y.; Lee, H. Y. Tetrahedron Lett. 2001, 42, 1057-1060.

30. Shang, Y. J.; Wang, Y. G. Synthesis 2002, 2002, 1663-1668.

31. Shankar, B. B.; Yang, D. Y.; Girton, S.; Ganguly, A. K. Tetrahedron Lett. 1998, 39, 2447-2448.

32. Kumar, R. S.; Rajesh, S. M.; Perumal, S.; Yogeeswari, P.; Sriram, D. Tetrahedron Asymm. 2010, 21, 1315-1327.

33. Chen, S.; Ren, J.; Wang, Z. Tetrahedron 2009, 65, 9146-9151.

34. Okazaki, R. Yuki Gosei Kagaku Kyokaishi 1988, 46, 1149-1163.

35. Tokitoh, N.; Okazaki, R. Pol. J. Chem. 1998, 72, 971-1000. 
36. Rohr, U.; Schatz, J.; Sauer, J. Eur. J. Org. Chem. 1998, 2875-2883.

37. Bachrach, S. M.; Jiang, S. J. Org. Chem. 1999, 64, 8248-8255.

38. Liao, H. Y.; Su, M. D.; Chu, S. Y. Chem. Phys. 2000, 261, 275-287.

39. Orlova, G.; Goddard, J. D. J. Org. Chem. 2001, 66, 4026-4035.

40. Litvinov, V. P.; Dyachenko, V. D. Russ. Chem. Rev. 1997, 66, 923-951.

41. Segi, M.; Nakajima, T.; Suga, S.; Murai, S.; Ryu, I.; Ogawa, A.; Sonoda, N. J. Am. Chem. Soc. 1988, 110, 1976-1978.

42. Segi, M.; Takahashi, M.; Nakajima, T.; Suga, S.; Murai, S.; Sonoda, N. Tetrahedron Lett. 1988, 29, 6965-6968.

43. Segi, M.; Koyama, T.; Nakajima, T.; Suga, S.; Murai, S.; Sonoda, N. Tetrahedron Lett. 1989, 30, 20952098.

44. Segi, M.; Kato, M.; Nakajima, T. Tetrahedron Lett. 1991, 32, 7427-7430.

45. Li, G. M.; Segi, M.; Nakajima, T. Tetrahedron Lett. 1992, 33, 3515-3518.

46. Segi, M.; Takahashi, T.; Ichinose, H.; Li, G. M.; Nakajima, T. Tetrahedron Lett. 1992, 33, 7865-7868.

47. Li, G. M.; Niu, S.; Segi, M.; Zingaro, R. A,; Yamamoto, H.; Watanabe, K.; Nakajima, T.; Hall, M. B. J. Org. Chem. 1999, 64, 1565-1575.

48. Segi, M. Yuki Gosei Kagaku Kyokaishi 2003, 61, 661-669.

49. Segi, M.; Tanno, K.; Kojima, M.; Honda, M.; Nakajima, T. Tetrahedron Lett. 2007, 48, 2303-2306.

50. Petersson, G. A.; Bennett, A.; Tensfeldt, T. G.; Al-Laham, M. A.; Shirley, W. A.; Mantzaris, J. J. Chem. Phys. 1988, 89, 2193-2218.

51. Petersson, G. A.; Al-Laham, M. A. J. Chem. Phys. 1991, 94, 6081-6090.

52. (a) Frisch, M. J.; Head-Gordon, M.; Pople, J. A. Chem. Phys. Lett. 1990, 166, 275-280.; (b); Chem. Phys. Lett. 1990, 166, 281-289.; (c) Head-Gordon, M.; Pople, J. A.; Frisch, M. J. Chem. Phys. Lett. 1988, 153, 503-506;; (d) Head-Gordon M. T. Chem. Phys. Lett. 1994, 220, 122-128.; (e) Saebø, S.; Almlöf, J. Chem. Phys. Lett. 1989, 154, 83-89.

53. Frisch, J. et al., Gaussian, Inc., Wallingford CT, 2016. Gaussian 09, Revision.

54. Parr, R. G.; Szentpály, L. v.; Liu, S., J. Am. Chem. Soc. 1999, 121, 1922-1924.

55. Parr, R. G.; Pearson, R. G., J. Am. Chem. Soc. 1983, 105, 7512-7516.

56. Parr, R. G.; Weitao, Y., Oxford University Press: 1994.

57. Kohn, W.; Sham, L. J., Phys. Rev. 1965, 140, A1133-A1138.

58. Domingo, L. R.; Chamorro, E.; Pérez, P., J. Org. Chem. 2008, 73, 4615-4624.

59. Domingo, L. R.; Pérez, P.; Sáez, J. A., RSC Adv. 2013, 3, 1486-1494.

60. Domingo, L. R.; Aurell, M. J.; Pérez, P.; Contreras, R., Tetrahedron. 2002, 58, 4417-4423.

61. Jaramillo, P.; Domingo, L. R.; Chamorro, E.; Pérez, P., J. Mol. Struct.: THEOCHEM 2008, 865, 6872.

62. Domingo, L., Molecules. 2016, 21, 1319.

63. Domingo, L. R.; Sáez, J. A., J. Org. Chem. 2010, 76, 373-379.

64. Domingo, R. L.; Ríos-Gutiérrez, M.; Acharjee, N., Molecules. 2019, 24. 